\title{
PENERAPAN STRATEGI PQ4R UNTUK MENINGKATKAN KETERAMPILAN MEMBACA INTENSIF SISWA KELAS V MENGGUNAKAN MEDIA TEKS CERITA RAKYAT RONGGA PADA SEKOLAH DASAR KATOLIK PAU NDOA KOTA KOMBA, MANGGARAI TIMUR
}

\author{
Ferdinandus Tetu ${ }^{1}$, I Wayan Simpen ${ }^{2}$, Putu Sutama ${ }^{3}$ \\ Manggarai Timur, Flores ${ }^{1}$ \\ Fakultas Ilmu Budaya, Universitas Udayana ${ }^{2,3}$ \\ e-mail:fernandoymf@gmail.com, Wyn.simpen@gmail.com, $\underline{\text { Pt_sutama@unud.ac.id }}$
}

\begin{abstract}
Abstrak-Penelitian ini bertujuan untuk meningkatkan kemampuan membaca intensif siswa kelas V SDK Pau Ndoa menggunakan strategi PQ4R dan media teks cerita rakyat Rongga. Penelitian ini menggunakan metode campuran yakni kombinasi antara metode kuantitatif dan kualitatif khususnya model concurrent (kombinasi campuran) dengan bobot metode kualitatif lebih tinggi dari pada metode kuantitatif. Metode dan teknik pengumpulan data dilakukan dengan menggunakan observasi, kuesioner, dan tes. Data kuantitatif dianalisis menggunakan metode statistik sederhana dalam bentuk persentase (\%), sedangkan data kualitatif dianalisis dengan menggunakan kata-kata. Terdapat tiga aspek penilaian kemampuan membaca intensif siswa, yakni kecepatan membaca, pemahaman isi, dan simpulan isi cerita. Rentang nilai yang digunakan sebagai standar penilaian hasil akhir belajar siswa terbagi atas lima kategori, yakni sangat kurang (<40), kurang (41--55), cukup (56--70), baik (71--85), dan baik sekali (86--100). Hasil penelitian ini menunjukkan adanya peningkatan pada siklus I dan siklus II. Pada tahap pratindakan, dari Sembilan belas siswa SDK Pau Ndoa, Kabupaten Manggarai Timur yang dijadikan subjek penelitian, hanya dua orang siswa dengan persentase $11 \%$ yang dinyatakan tuntas mencapai standar KKM 60 yang diberlakukan di sekolah tersebut. Pada siklus I terdapat sembilan orang siswa dengan persentase $47 \%$ yang mencapai standar KKM atau terjadi peningkatan sebesar 36\%. Pada siklus II semua siswa telah mencapai KKM. Ada dua faktor yang memengaruhi peningkatan kemampuan membaca intensif siswa SDK Pau Ndoa, yakni faktor internal yang meliputi penguasaan terhadap strategi PQ4R, peningkatan motivasi dan rasa percaya diri dalam membaca, dan peningkatan kemampuan membaca cepat. Sebaliknya, faktor eksternal meliputi penerapan strategi PQ4R dan penggunaan cerita lokal sebagai sumber belajar.
\end{abstract}

Kata Kunci: membaca intensif, cerita lokal, strategi $P Q 4 R$

\section{PENDAHULUAN}

Pada hakikatnya pengajaran dan pembelajaran bahasa Indonesia di sekolah merupakan suatu upaya peningkatan performansi dan kompetensi siswa dalam berkomunikasi, baik secara lisan maupun tertulis. Pemerolehan performansi dan kompetensi berbahasa Indonesia sangat berpengaruh terhadap kemampuan berpikir (bernalar). Terdapat empat kemampuan dasar berbahasa yang perlu dikuasai siswa dalam upaya pemerolehan performansi dan kompetensi tersebut, yakni kemampuan mendengarkan, berbicara, membaca, dan menulis.

Untuk mengetahui dan memahami pesanpesan penulis yang terdapat dalam semua karya tulisnya, keterampilan membaca menjadi keterampilan yang sangat penting untuk dikuasai 
para pembaca dalam hal ini para siswa. Membaca merupakan suatu proses yang dilakukan dan digunakan oleh pembaca untuk memperoleh pesan yang hendak disampaikan oleh penulis melalui media kata-kata/bahasa tulis (Tarigan, 2008 dalam Dalman, 2017:7).

Hasil praobservasi menunjukkan bahwa keterampilan membaca siswa kelas V SDK Pau Ndoa masih kurang maksimal dan belum mencapai target yang diharapkan. Kemampuan membaca dalam hati hampir seluruh siswa khususnya membaca intensif yang berfokus pada membaca pemahaman masih jauh dari harapan. Kurangnya kemampuan membaca intensif para siswa pada sekolah tersebut disebabkan oleh beberapa hal, seperti siswa belum memahami cara membaca intensif dan strategi pembelajaran membaca yang diterapkan belum sepenuhnya membangun prestasi para siswa melalui membaca intensif. Hal ini berdampak pada rendahnya prestasi kemampuan membaca intensif yang diperoleh setiap siswa. Banyak nilai siswa yang belum mencapai kriteria ketuntasan minimal (KKM) yang ditentukan oleh sekolah dasar Katolik Pau Ndoa yakni 60.00 untuk mata pelajaran bahasa Indonesia.

Pembelajaran bahasa Indonesia khususnya membaca intensif yang diterapkan di SDK Pau Ndoa sangat sedikit menggunakan sumber-sumber belajar berbasis lingkungan sekitar atau terkesan sangat tidak diperhatikan. Sementara para siswa menjalani kehidupan dan berkomunikasi dengan sesamanya di lingkungannya masing-masing. Fill (2001:2) dalam Rambut et al. (2015:41) menyatakan bahwa tanda-tanda lingual mendeskripsikan lingkungan di mana orang hidup berinteraksi, saling terkait, dan saling bergantung. Dengan demikian, sumber-sumber bacaan tentang lingkungannya sangat penting untuk diterapkan dalam kegiatan membaca agar para siswa mengenal lingkungannya dengan baik dan tidak tercerabut dari lingkungannya. Namun, dalam kenyataannya, pada tahapan observasi di SDK Pau Ndoa, ditemukan bahwa pembelajaran berbasis lingkungan di sekolah tersebut tidak diterapkan dengan baik karena dianggap kurang relevan atau tidak memiliki makna dan pesan pendidikan. Para guru lebih cenderung menggunakan sumber-sumber belajar di luar lingkungan belajar siswa yang kurang relevan dengan lingkungan belajar anak, seperti cerita Cinderella dan Pinokio.

\section{METODE PENELTIAN}

Penelitian ini menggunakan metode kombinasi, yakni kuantitatif dan kualitatif. Metode kombinasi yang digunakan adalah model concurrent (kombinasi campuran) dengan bobot metode kualitatif yang lebih tinggi dari pada metode kuantitatif. Pada model ini ada metode yang primer dan metode sekunder. Metode primer digunakan untuk memperoleh data utama dan metode sekunder digunakan untuk memperoleh data guna mendukung data yang diperoleh dari metode primer (Sugiyono, 2017:412).

\section{TEORI}

Untuk membedah masalah dalam penelitian digunakan beberapa teori membaca, yakni teori membaca Dalman, teori membaca insentif Harmer, teori membaca Tarigan. Selain itu, juga didukung oleh teori menurut Daniel yakni penggunaan kata Tanya $5 W+1 H$, teori Friend, dan teori menurut Arikunto dan Jabar 
untuk menganalisis data kualitatif penyimpulan isi cerita.

\section{PEMBAHASAN}

$\mathrm{Bab}$ ini mendeskripsikan temuan dan pembahasan kemampuan membaca intensif siswa SDK Pau Ndoa sebelum dan sesudah penerapan strategi PQ4R serta faktor-faktor yang memengaruhi peningkatan kemampuan membaca intensif mereka. Data yang dianalisis dikumpulkan berdasarkan hasil pengamatan, tes dalam bentuk pretest dan tes per siklus setelah tindakan. Di samping itu, juga diperoleh dari kuesioner yang dibagikan kepada para siswa.

\section{Analisis Kualitatif Hasil Observasi Pratindakan}

Berdasarkan hasil observasi terhadap guru Bahasa Indonesia dan para siswa kelas V SDK Pau Ndoa, ditemukan beberapa kekurangan yang menjadi kendala tidak maksimalnya kemampuan membaca intensif mereka untuk mata pelajaran Bahasa Indonesia.

Secara terperinci kendala-kendala tersebut, seperti sekolah tidak memiliki buku pegangan siswa sebagai sumber belajar siswa sesuai dengan KTSP (Kurikulum Tingkat Satuan Pendidikan), guru masih mengadopsi bahan ajar dari Kurikulum Berbasis Kompetensi dalam bentuk buku pegangan guru dan siswa, guru masih menerapkan strategi konvensional yang didominasi oleh metode ceramah dalam mengajarkan materi membaca pada mata pelajaran Bahasa Indonesia, guru tidak membuat persiapan mengajar berupa rencana pelaksanaan pembelajaran (RPP) sehingga pembelajaran kurang terarah dan pencapaian tujuan pembelajaran sulit diukur, guru tidak

memberikan kesempatan kepada siswa untuk bertanya, baik kepada guru maupun kepada sesama siswa atau kepada narasumber lainnya tentang topik bacaan yang diajarkan, dan guru tidak memahami strategi PQ4R untuk meningkatkan kemampuan membaca intensif siswa.

\section{Kemampuan Membaca Intensif Siswa pada Tahap Prasiklus}

Hasil penilaian kemampuan membaca pemahaman siswa kelas V SDK Pau Ndoa pada tahap prasiklus didasarkan pada kecepatan membaca, pemahaman isi, dan penyimpulan isi. Dari penetapan kemampuan ini diperoleh nilai akhir setiap siswa dalam membaca intensif khususnya untuk membaca pemahaman bertema cerita rakyat Rongga. Nilai akhir tersebut dianalisis secara kualitatif dan kuantitatif. Analisis kuantitatif diuraikan pada tabel berikut.

\section{Tabel 4.1 Data Nilai Akhir Siswa Tahap Prasiklus}




\begin{tabular}{|c|c|c|c|c|c|c|c|}
\hline \multirow{2}{*}{ NO } & \multirow{2}{*}{ Nama Siswa } & \multicolumn{4}{|c|}{ Skor } & \multirow{2}{*}{ KMP } & \multirow{2}{*}{ Keterangan } \\
\hline & & KKM & KPM & PI.1 & PI.2 & & \\
\hline 1 & A. Daren & \begin{tabular}{|l|}
60 \\
\end{tabular} & 49 & 57 & 40 & 49 & Tidak Tuntas \\
\hline 2 & A. Olan & 60 & 45 & 62 & 40 & 49 & Tidak Tuntas \\
\hline 3 & B. Jehanul & 60 & 49 & 57 & 60 & 55 & Tidak Tuntas \\
\hline 4 & F. Jeniur & 60 & 50 & 71 & 60 & 60 & Tuntas \\
\hline 5 & H. Majeng & 60 & 50 & 76 & 40 & 55 & Tidak Tuntas \\
\hline 6 & I. Rani & 60 & 54 & 67 & 40 & 54 & Tidak Tuntas \\
\hline 7 & M. Jemeon & 60 & 54 & 62 & 60 & 59 & Tidak Tuntas \\
\hline 8 & M. Mujur & 60 & 54 & 67 & 40 & 54 & Tidak Tuntas \\
\hline 9 & M. Kuwang & 60 & 54 & 67 & 60 & 60 & Tuntas \\
\hline 10 & M. Juma & 60 & 54 & 52 & 40 & 49 & Tidak Tuntas \\
\hline 11 & M. Dani & 60 & 67 & 24 & 60 & 50 & Tidak Tuntas \\
\hline 12 & M. Jemiun & 60 & 60 & 43 & 40 & 48 & Tidak Tuntas \\
\hline 13 & M. Nalo & 60 & 56 & 52 & 40 & 49 & Tidak Tuntas \\
\hline 14 & K. Roka & 60 & 59 & 67 & 40 & 55 & Tidak Tuntas \\
\hline 15 & Q. Liti & 60 & 61 & 52 & 60 & 58 & Tidak Tuntas \\
\hline 16 & R. Jano & 60 & 64 & 57 & 40 & 54 & Tidak Tuntas \\
\hline 17 & R. Bombang & 60 & 51 & 52 & 40 & 48 & Tidak Tuntas \\
\hline 18 & T. Ola & 60 & 71 & 52 & 40 & 54 & Tidak Tuntas \\
\hline 19 & Y. Wana & 60 & 68 & 48 & 40 & 52 & Tidak Tuntas \\
\hline \multicolumn{3}{|c|}{ Jlh } & 1070 & 1085 & 880 & 1012 & \\
\hline \multicolumn{6}{|c|}{ Rerata } & 53 & \\
\hline \multicolumn{6}{|c|}{ Jlh Siswa yang Memcapai KKM } & 2 & \\
\hline \multicolumn{6}{|c|}{ Presentase Yang Mencapai KKM } & 11 & \\
\hline
\end{tabular}

Keterangan Skor:

KKM : Kriteria Ketuntasan Minimal

KPM : Jumlah Kata per Menit

PI. 1 : Pemahaman Isi

PI.2 : Penyimpulan Isi

Keterangan Nilai:

1. Nilai $\geq 60$ : Tuntas

2. Nilai<60 : Tidak Tuntas

Tabel 4.1 menjelaskan bahwa rerata nilai yang diperoleh sembilan belas siswa untuk keterampilan membaca pemahaman adalah 42 . Hanya terdapat dua orang siswa (11\%) dari sembilan belas siswa yang dinyatakan tuntas. Sebaliknya tujuh belas orang siswa lainnya masih berada di bawah standar KKM yang sudah ditetapkan SDK Pau Ndoa. Untuk lebih jelas, persentase frekuensi hasil belajar siswa pada tahap pratindakan dapat digambarkan melalui tabel frekuensi berikut.
Tabel 4.2 Data Frekuensi Hasil Belajar Siswa tahap Pra Siklus

\begin{tabular}{|c|l|c|c|}
\hline \multicolumn{4}{|c|}{ FREKUENSI HASIL BELAJAR SISWA PRA TINDAKAN } \\
\hline \hline NO & \multicolumn{1}{|c|}{ INTERVAL NILAI } & FREKUENSI & PERSENTASE \% \\
\hline 1 & Sangat kurang $(<\mathbf{4 0})$ & 0 & 0 \\
\hline 2 & kurang $(\mathbf{4 1}-\mathbf{5 5})$ & 14 & 74 \\
\hline 3 & cukup $\mathbf{5 6}-\mathbf{- 7 0})$ & 5 & 26 \\
\hline 4 & baik (71 -- 85) & 0 & 0 \\
\hline 5 & baik sekali $(\mathbf{8 6}-\mathbf{1 0 0})$ & 0 & 0 \\
\hline \multicolumn{2}{|l|}{ Total } & 19 & 100 \\
\hline
\end{tabular}

Dari interval nilai yang terdapat pada tabel 4.2, diketahui bahwa tidak ada satu pun siswa dari total sembilan belas siswa yang mengikuti pembelajaran bahasa Indonesia yang berada pada kategori baik dan sangat baik. Terdapat dua siswa yang dinyatakan tuntas mencapai standar KKM 60 yang diberlakukan pada sekolah tersebut. Sebaliknya tujuh belas siswa lainnya memperoleh nilai di bawah KKM.

Secara kualitatif hampir seluruh siswa belum menguasai aspek pemahaman isi bacaan yang berhubungan dengan menjawab pertanyaan dan menyimpulkan isi cerita. Pada aspek menjawab pertanyaan isi bacaan, kebanyakan siswa belum mampu menjawab pertanyaan dengan kata tanya who (siapa) untuk mengidentifikasi karakter dalam bacaan dan membuat hubungan antarkarakter dan mendeskripsikannya. Kata tanya what (apa) untuk mengidentifikasi kejadian, membuat hubungan antarkejadian tersebut dan membuat hubungan antara karakter dan kejadian, dan menndeskripsikannya. Kata Tanya where (di mana) untuk mengidentifikasi semua tempat dalam bacaan dan membuat hubungan antartempat tersebut, kejadian dan karakter dan mendeskripsikannya. Kata tanya when (kapan) untuk mengidentifikasi semua faktor waktu dan membuat hubungan antara faktor waktu, tempat, kejadian, dan karakter serta mendeskripsikannya. Kata tanya why (mengapa) untuk mengidentifikasi sebab-sebab kejadian dan membuat hubungan sebab akibat terhadap karakter kejadian, tempat atau waktu, dan mendeskripsikannya. Kata tanya how (bagaimana) untuk mengidentifikasi bagaimana kejadian terjadi dan membuat hubungan kejadian yang terjadi dan faktor lainnya. 
Pada aspek penyimpulan isi, hampir seluruh siswa belum berhasil mereproduksi atau menulis kembali kalimat tunggal dengan baik, belum berhasil menggabungkan atau menyatukan dua kalimat atau lebih (dari satu paragraf) dengan baik. Di samping itu, juga belum berhasil menyatukan atau mengintegrasikan ide lebih dari satu paragraf.

\section{Kemampuan Membaca Intensif Siswa setelah Penerapan Strategi PQ4R pada Tahap Siklus I}

Kemampuan membaca intensif siswa kelas $\mathrm{V}$ SDK Pau Ndoa pada siklus I dideskripsikan dalam bentuk data kualitatif dan kuantitatif. Hasil penilaian didasarkan pada aspek kecepatan membaca, pemahaman isi, dan penyimpulan isi. Nilai akhir setiap siswa dalam membaca intensif khususnya untuk membaca pemahaman bertema cerita rakyat Rongga dirangkum dari ketiga aspek tersebut. Nilai akhir tersebut dianalisis secara kualitatif dan kuantitatif. Tabel berikut menyajikan analisis secara kuantitatif.

\section{Tabel 4.3 Data Nilai Akhir Siswa Siklus I}

\begin{tabular}{|c|c|c|c|c|c|c|c|}
\hline \multirow{2}{*}{ No } & \multirow{2}{*}{ Nama Siswa } & \multicolumn{4}{|c|}{ Skor } & \multirow{2}{*}{ KMP } & \multirow{2}{*}{ Keterangan } \\
\hline & & KKM & KPM & PI.1 & PI.2 & & \\
\hline 1 & A. Daren & 60 & 82 & 63 & 40 & 62 & Tuntas \\
\hline 2 & A. Olan & 60 & 84 & 63 & 40 & 62 & Tuntas \\
\hline 3 & B. Jehanul & 60 & 77 & 63 & 40 & 60 & Tuntas \\
\hline 4 & F. Jeniur & 60 & 63 & 75 & 40 & 59 & Tidak Tuntas \\
\hline 5 & H. Majeng & 60 & 64 & 88 & 60 & 71 & Tuntas \\
\hline 6 & I. Rani & 60 & 74 & 79 & 60 & 71 & Tuntas \\
\hline 7 & M. Jemeon & 60 & 68 & 67 & 60 & 65 & Tuntas \\
\hline 8 & M. Mujur & 60 & 81 & 71 & 80 & 77 & Tuntas \\
\hline 9 & M. Kuwang & 60 & 73 & 71 & 60 & 68 & Tuntas \\
\hline 10 & M. Juma & 60 & 84 & 54 & 40 & 59 & Tidak Tuntas \\
\hline 11 & M. Dani & 60 & 50 & 58 & 40 & 49 & Tidak Tuntas \\
\hline 12 & M. Jemin & 60 & 63 & 54 & 40 & 52 & Tidak Tuntas \\
\hline 13 & M. Nalo & 60 & 52 & 63 & 40 & 52 & Tidak Tuntas \\
\hline 14 & K. Roka & 60 & 71 & 71 & 60 & 67 & Tuntas \\
\hline 15 & Q. Liti & 60 & 52 & 58 & 40 & 50 & Tidak Tuntas \\
\hline 16 & R. Jano & 60 & 52 & 58 & 40 & 50 & Tidak Tuntas \\
\hline 17 & R. Bombang & 60 & 59 & 58 & 40 & 52 & Tidak Tuntas \\
\hline 18 & T. Ola & 60 & 57 & 58 & 60 & 58 & Tidak Tuntas \\
\hline 19 & Y. Wana & 60 & 78 & 54 & 40 & 57 & Tidak Tuntas \\
\hline \multicolumn{3}{|c|}{ Jlh } & & & & 1143 & \\
\hline \multicolumn{6}{|c|}{ Rerata } & 60 & \\
\hline \multicolumn{6}{|c|}{ Jlh Siswa yang Memcapai KKM } & 9 & \\
\hline \multicolumn{6}{|c|}{ Presentase Yang Mencapai KKM } & 47 & \\
\hline
\end{tabular}

Keterangan Skor:
KKM : Kriteria Ketuntasan Minimal
KPM : Jumlah Kata per Menit
PI. 1 : Pemahaman Isi
PI. 2 : Penyimpulan Isi

Keterangan Nilai:
1. Nilai $\geq 60$
: Tuntas
2. Nilai $<60$
: Tidak Tuntas

Tabel 4.3 menjelaskan bahwa rerata nilai yang diperoleh Sembilan belas orang siswa adalah 63. Terdapat dua belas orang siswa yang mendapatkan nilai tuntas dengan persentase $63 \%$, sedangkan tujuh siswa lainnya masih di bawah standar KKM yang sudah ditetapkan oleh sekolah.

Persentase hasil belajar siswa pada siklus I dapat digambarkan melalui tabel frekuensi berikut.

\section{Tabel 4.4 Data Frekuensi Hasil Belajar Siswa} Siklus I

\begin{tabular}{|c|l|c|c|}
\hline \multicolumn{5}{|c|}{ FREKUENSI HASIL BELAJAR SISWA SIKLUS I } \\
\hline \hline NO & INTERVAL NILAI & FREKUENSI & PERSENTASE \\
\hline 1 & Sangat kurang (<40) & 0 & 0 \\
\hline 2 & Kurang (41 -- 55) & 6 & 32 \\
\hline 3 & Cukup (56 -- 70) & 10 & 53 \\
\hline 4 & Baik (71 -- 85) & 3 & 16 \\
\hline 5 & Baik sekali (86 -- 100) & 0 & 0 \\
\hline \multicolumn{2}{|c|}{ Total } & 19 & 100 \\
\hline
\end{tabular}

Dari interval nilai yang terdapat pada tabel 4.4 khusus pada kategori cukup, nilai yang digunakan dimulai dari 60 sesuai dengan KKM SD Pau Ndoa. Dengan demikian, dari sembilan belas siswa kelas V yang mengikuti pembelajaran Bahasa Indonesia dengan materi Cerita Rakya Rongga, terdapat sembilan orang siswa yang nilainya sudah mencapai standar KKM dengan perincian, yaitu enam orang siswa yang berada pada kategori cukup dan tiga orang siswa telah mencapai kategori baik. Di pihak lain, sepuluh siswa lainnya masih memperoleh nilai di bawah KKM.

Hasil belajar siswa terbagi menjadi lima rentangan nilai, yaitu $<40$ sebanyak 0 orang siswa dengan persentase $0 \%$, rentang nilai $41--55$ sebanyak enam orang siswa dengan persentase 
$32 \%$, rentang nilai 56--70 sebanyak sepuluh orang siswa dengan persentase $53 \%$, rentang nilai 71--85 sebanyak tiga orang siswa dengan persentase $16 \%$ dan rentangan nilai $81--100$ sebanyak 0 orang siswa dengan persentase $0 \%$.

Secara kualitatif, sepuluh siswa yang belum mencapai KKM, belum mampu menjawab pertanyaan dengan kata tanya what (apa) untuk mengidentifikasi kejadian, membuat hubungan antarkejadian tersebut, dan membuat hubungan antara karakter dan kejadian, serta mendeskripsikannya.

\section{Kemampuan Membaca Intensif setelah \\ Penerapan Strategi PQ4R pada siklus II}

Hasil penilaian kemampuan membaca intensif siswa kelas V SDK Pau Ndoa pada siklus II meliputi aspek kecepatan membaca, pemahaman isi, dan penyimpulan isi. Nilai akhir tersebut dianalisis secara kualitatif dan kuantitatif. Berikut disajikan tabel analisis nilai akhir siswa secara kuantitatif.

Tabel 4.5 Data Nilai Akhir Siswa Siklus II

\begin{tabular}{|c|c|c|c|c|c|c|c|}
\hline \multirow{2}{*}{ No } & \multirow{2}{*}{ Nama Siswa } & \multicolumn{4}{|c|}{ Skor } & \multirow{2}{*}{ KMIP } & \multirow{2}{*}{ Keterangan } \\
\hline & & KKM & KPM & PI.1 & PI.2 & & \\
\hline 1 & A. Daren & 60 & 75 & 77 & 80 & 77 & Tuntas \\
\hline 2 & A. Olan & 60 & 82 & 70 & 80 & 77 & Tuntas \\
\hline 3 & B. Jehanul & 60 & ss & 73 & 80 & 80 & Tuntas \\
\hline 4 & F. Jeniur & 60 & 74 & 77 & 80 & 77 & Tuntas \\
\hline 5 & H. Majeng & 60 & 94 & 90 & 80 & 88 & Tuntas \\
\hline 6 & I. Rani & 60 & 80 & 80 & 80 & 80 & Tuntas \\
\hline 7 & M. Jemeon & 60 & 73 & 83 & 80 & 79 & Tuntas \\
\hline 8 & M. Mujur & 60 & 98 & 70 & 60 & 76 & Tuntas \\
\hline 9 & M. Kuwang & 60 & 94 & 77 & 80 & 83 & Tuntas \\
\hline 10 & M. Juma & 60 & 86 & 67 & 60 & 71 & Tuntas \\
\hline 11 & M. Dani & 60 & 73 & 67 & 80 & 73 & Tuntas \\
\hline 12 & M. Jemiun & 60 & 91 & 83 & 80 & 85 & Tuntas \\
\hline 13 & M. Nalo & 60 & 89 & 87 & 80 & 85 & Tuntas \\
\hline 14 & K. Roka & 60 & 87 & 67 & 80 & 78 & Tuntas \\
\hline 15 & Q. Liti & 60 & 84 & 70 & 60 & 71 & Tuntas \\
\hline 16 & R. Jano & 60 & 73 & 60 & 60 & 64 & Tuntas \\
\hline 17 & R. Bombang & 60 & 79 & 77 & 60 & 72 & Tuntas \\
\hline 18 & T. Ola & 60 & 93 & 73 & 60 & 75 & Tuntas \\
\hline 19 & Y. Wana & 60 & 93 & 80 & 80 & 84 & Tuntas \\
\hline \multicolumn{6}{|c|}{ Ih } & 1477 & \\
\hline \multicolumn{6}{|c|}{ Rerata } & 78 & \\
\hline \multicolumn{6}{|c|}{ Jh Siswa yang Memcapai KKM } & 19 & \\
\hline \multicolumn{6}{|c|}{ Presentase Yang Mencapai KKM } & 100 & \\
\hline
\end{tabular}

Keterangan Skor:

KKM : Kriteria Ketuntasan Minimal
KPM : Jumlah Kata per Menit
PI. 1 : Pemahaman Isi
PI.2 : Penyimpulan Isi

Keterangan Nilai:
1. Nilai $\geq 60$
: Tuntas
Nilai $<60$
: Tidak Tuntas

Tabel 4.5 menjelaskan bahwa rerata nilai yang diperoleh Sembilan belas orang siswa SDK Pau Ndoa adalah 78. Keseluruhan Sembilan belas orang siswa tersebut dengan persentase 100\% sudah mencapai KKM mata pelajaran Bahasa Indonesia yang telah ditetapkan SDK Pau Ndoa. Persentase hasil belajar siswa pada siklus II dapat digambarkan melalui tabel frekuensi berikut.

\section{Tabel 4.6 Data Frekuensi Hasil Belajar Siswa Siklus II}

\begin{tabular}{|c|l|c|c|}
\hline \multicolumn{5}{|c|}{ FREKUENSI HASIL BELAJAR SISWA PRA TINDAKAN } \\
\hline \hline NO & \multicolumn{1}{|c|}{ INTERVAL NILAI } & FREKUENSI & PERSENTASE \\
\hline 1 & Sangat Kurang $(<40)$ & 0 & 0 \\
\hline 2 & Kurang $(\mathbf{4 1}-\mathbf{5 5})$ & 0 & 0 \\
\hline 3 & Cukup (56 -- 70) & 1 & 5 \\
\hline 4 & Baik (71 -- 85) & 15 & 79 \\
\hline 5 & Baik Sekali $(86--\mathbf{1 0 0})$ & 3 & 16 \\
\hline
\end{tabular}

Dari interval nilai yang terdapat pada tabel 4.6, terlihat bahwa dari total keseluruhan siswa yang berjumlah 19 orang, semuanya sudah mencapai nilai standar KKM yang diberlakukan pada SDK Pau Ndoa, Kabupaten Manggarai Timur. Hasil belajar siswa terbagi menjadi lima rentangan nilai, yaitu $<40$ sebanyak 0 orang siswa dengan persentase $0 \%$, rentang nilai $41--55$ sebanyak 0 orang siswa dengan persentase $0 \%$, rentang nilai 56--70 sebanyak satu orang siswa dengan persentase 5\%, rentang nilai 71--85 sebanyak lima belas orang siswa dengan persentase $79 \%$ dan rentangan nilai 81--100 sebanyak tiga orang siswa dengan persentase $16 \%$.

Secara kualitatif, para siswa telah menguasai aspek pemahaman isi bacaan yang berhubungan dengan menjawab pertanyaan dengan kata tanya $5 W+1 H$. Di samping itu, juga menyimpulkan isi cerita yang meliputi mereproduksi atau menulis kembali kalimat tunggal dengan baik, 
menggabungkan atau menyatukan dua kalimat atau lebih (dari satu paragraf) dengan baik dan menyatukan atau mengintegrasikan ide lebih dari satu paragraf.

\section{Faktor yang Memengaruhi Peningkatan Kemampuan Membaca Intensif Siswa Kelas V SDK Pau Ndoa}

Peningkatan kemampuan siswa dalam membaca intensif dipengaruhi oleh dua faktor utama. Dua faktor yang dimaksud, yakni faktor internal dan faktor eksternal. Kedua faktor ini sangat erat kaitannya dengan motivasi. Brown (2000:165) dalam Dewi (2015:6) berpendapat bahwa motivasi secara tipikal dapat dibedakan atas motivasi intrinsik dan motivasi ekstrinsik. Aktivitas-aktvitas yang termotivasi secara intrinsik adalah aktivitas yang tidak ada imbalannya. Sebaliknya, perilaku yang termotivasi secara ekstrinsik dipakai untuk kepentingan atau imbalan dari luar diri, bahkan umpan balik tertentu atau karena adanya tekanan dari pihak luar. Rangkaian kedua motivasi ini dapat dipakai oleh semua kelas bahasa di seluruh dunia karena saling melengkapi. Lebih lanjut, Slameto dalam (Umareani, 2014:4) menggolongkan faktor yang mempengaruhi hasil belajar menjadi dua bagian, yaitu faktor internal dan eksternal.

\section{(1) Faktor Internal}

Faktor internal merupakan faktor yang muncul dari dalam diri siswa. Ada sejumlah faktor internal yang memengaruhi peningkatan kemampuan membaca intesif siswa-siswa SDK Pau Ndoa, Kabupaten Manggarai Timur, yakni mereka telah mengetahui istilah strategi PQ4R, mereka menyukai pengajaran dengan strategi PQ4R, mereka menjadi percaya diri untuk memastikan bahwa bacaan yang dibaca telah dikuasai, mereka merasa siap untuk membaca dan memahami bacaan yang ditugaskan, mereka merasa mudah memahami bacaan dalam pelajaran bahasa Indonesia karena kecepatan membaca disesuaikan dengan waktu yang tersedia dan mereka senang bila diminta untuk membaca bahan bacaan yang diberikan oleh guru. Meskipun demikian, dari faktor internal pada kuesioner setelah posttest siklus II, masih ada sebagian kecil siswa yang kurang percaya diri untuk memastikan bahwa bacaan yang dibaca telah dikuasai dan merasa tidak siap untuk membaca dan memahami bacaan yang ditugaskan.

\section{(2) Faktor eksternal}

Faktor eksternal merupakan faktor yang datangnya dari luar siswa. Faktor-faktor tersebut sudah membangkitkan semangat para siswa kelas V SDK Pau Ndoa, Desa Komba, Kabupaten Manggarai Timur dalam mengikuti proses pembelajaran bahasa Indonesia khususnya dalam membaca intensif. Faktor-faktor eksternal tersebut meliputi penerapan strategi PQ4R, suruhan kepada siswa untuk membaca sesuai dengan standar kecepatan membaca, sumber bacaan yang mudah dimengerti, dan suasana kelas yang diciptakan untuk memengaruhi keaktifan siswa dalam mengikuti pelajaran bahasa Indonesia.

\section{SIMPULAN}

Berdasarkan hasil penelitian, ditarik simpulan bahwa pada tahap pratindakan sebelum diterapkan strategi PQ4R pada pembelajaran bahasa Indonesia dengan materi membaca intensif khususnya dalam memahami isi bacaan pada siswa kelas V SDK Pau Ndoa, Desa Komba, Kabupaten Manggarai Timur, ditemukan bahwa pada kegiatan guru khususnya pada kegiatan elaborasi tidak satu pun kegiatan yang dilakukan guru. Berdasarkan nilai akhir pada tahap prasiklus, hanya dua orang siswa (11\%) yang dinyatakan tuntas mencapai standar KKM 60 yang diberlakukan pada SDK Pau Ndoa. Setelah tindakan pada siklus I, terjadi peningkatan kemampuan membaca intensif sebesar $36 \%$. Terdapat sembilan orang siswa 
dengan persentase $47 \%$ mencapai standar KKM. Pada siklus II semua siswa telah mencapai KKM. Peningkatan kemampuan membaca intensif siswa SDK Pau Ndoa dipengaruhi oleh dua faktor utama, yakni faktor internal yang meliputi pemahaman dan rasa suka terhadap langkahlangkah strategi PQ4R, memiliki rasa percaya diri untuk memastikan bahwa bacaan yang dibaca telah dikuasai, memiliki kesiapan untuk membaca dan memahami bacaan yang ditugaskan, memiliki kecepatan membaca sesuai dengan waktu yang tersedia dan rasa senang bila diminta untuk membaca bahan bacaan yang diberikan oleh guru. Di pihak lain, faktor eksternal meliputi penerapan strategi PQ4R, pengaturan standar kecepatan membaca siswa, sumber bacaan yang mudah dimengerti dan suasana kelas yang diciptakan untuk memengaruhi keaktifan siswa dalam mengikuti pelajaran bahasa Indonesia.

\section{DAFTAR PUSTAKA}

Arikunto, Suharsimi dkk. 2012. Penelitian

Tindakan Kelas. Jakarta: Bumi Aksara.

Arka, I Wayan dkk. 2011. Nunu Nange Ngaja Rongga, Cerita Bahasa Rongga, Stories From Rongga. Maumere: Anggota IKAPI Seminari Tinggi Ledalero.

Arka, I Wayan. 2016. Bahasa Rongga (Diskripsi, Tipologi, dan Teori). Jakarta: Universitas Katolik Indonesia Atma Jaya.

Chin. Shao Joyce. 2010. Investigating the Summary Writing Performance of University Students in Taiwan.

Da Silva, Marietta Anna. 2011. Membuat Penelitian. Jakarta: Native Indonesia.

Dalman. 2017. Keterampilan Membaca. Jakarta:

PT Raja Grafindo Persada.

Departemen Pendidikan dan Kebudayaan 1995.

Kamus Besar Bahasa Indonesia. Jakarta: Balai Pustaka.

Dewi, Ni Nyoman Astiti et al. 2015. Pembelajaran Bahasa Daerah Bali pada Siswa Dwibahasa kelas VII SLTP di
Sekolah High Scope Indonesia-Bali. https://www.neliti.com/journals/linguistik a-buletin-ilmiah-program-magisterlinguistik-universitas-udayana.

Gozales, N.I.P. 2010. Teaching English Through Stories: A meaningful and fun way for children to learn the language. Profile, 12 (1), 95 - 105.

Harmer, Jeremi. 2001. The Practice of English Language Teaching. Third Edition. Longmen elt.

Ismawati, Esti. 2012. Metode Penelitian (Pendidikan Bahasa dan Sastra). Yogyakarta: Ombak.

Kridalaksana, Harimurti. 2011. Kamus Linguistik Edisi Keempat. Jakarta: Gramedia Pustaka Utama.

Nuraeni, 2010. Gangguan Emosi dan Perilaku. Bandung: Universitas Pendidikan Indonesia.

Nurgiyantoro, Burhan. 1995. Teori Pengkajian Fiksi. Yogyakarta: Gadjah Mada University Press.

Rambut, Kanisius et al. 2015. Ecolinguistic Perspective of Kerapingan Culture. eJournal of Linguistics, [S.1.], p. 40--53, oct. 2015. ISSN 2442-7586. Terdapat dalam:<https://ojs.unud.ac.id/index.php/e ol/articl e/view/16129>. Diunduh pada tanggal 8 Januari 2019.

Satory, Djam'an dan Komariah, Aan. 2014. Metodologi Penelitian Kualitatif. Bandung: Alfabeta.

Semi, M. Atar. 1993. Anatomi Sastra. Padang: Angkasa Raya.

Simpen, I Wayan. 2008. Pelangi Bahasa Indonesia. Denpasar: Pustaka Larasan.

Soeparno. 2002. Dasar-Dasar Linguistik Umum. Yogyakarta: Tiara Wacana Yogya.

Sugiyono. 2014. Metode Penelitian Kuantitatif Kualitatif dan $R \& D$. Bandung: Alfabeta.

Sugiyono. 2017. Metode Penelitian Kuantitatif, Kualitatif dan Kombinasi (Mixed Methods). Bandung: CV, Alfabeta.

Sutama, Putu. 2017. Konsepsi Kesejahteraan dalam Teks Budaya Bali Telaah 
Antropolinguistik. PROSIDING Seminar

Nasional Sastra dan Budaya II. Fakultas

Ilmu Budaya. Universitas Udayana.

Tarigan, Henry Guntur. 1984. Membaca sebagai

Suatu Keterempialan Berbahasa.

Bandung: Angkasa.

Tarigan, Henry Guntur. 1994. Membaca sebagai

Suatu Keterampilan Berbahasa.

Bandung: ANGKASA.

Tarigan, Henry Guntur. 2009. Metodologi

Angkasa.

Pengajaran Bahasa 2. Bandung:

Theyagu. Daniel \& Daniel Sandra. 2014.

Extremely Busy People's Guide to Read

Faster! Memorize Better! Think Clearer!.

Xlibris LLC.

Troike, Muriel Sawille. 2006. Intorducting Second Language Acquisition. Cambrige Univercity Press. 